gs 5

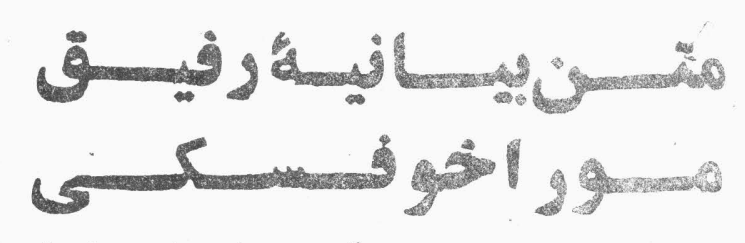

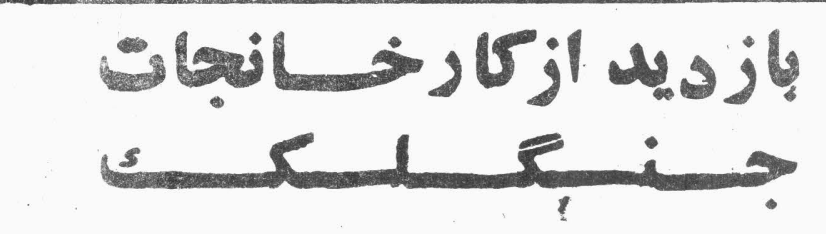

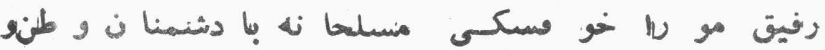

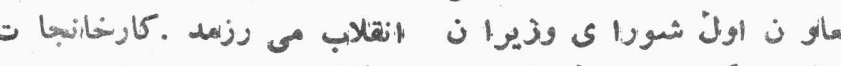

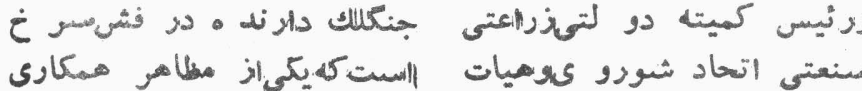

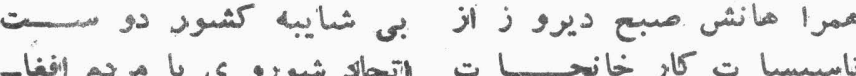

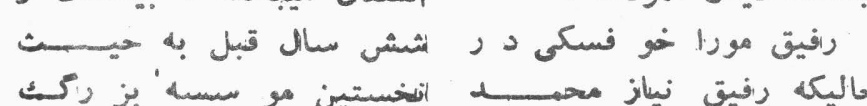

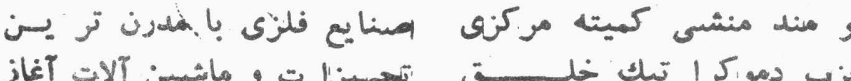

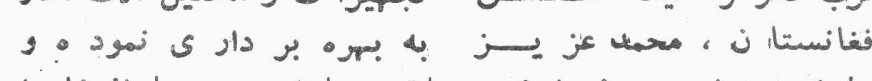

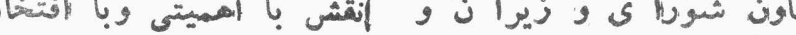

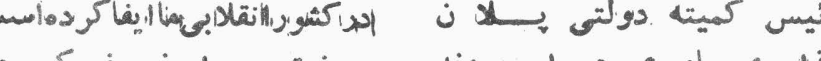

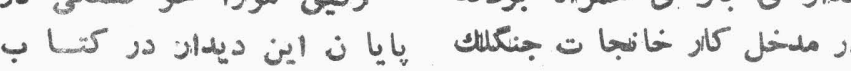

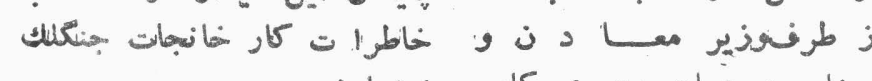

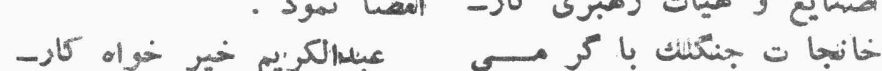

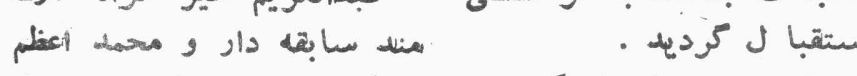

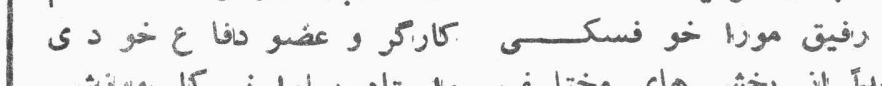

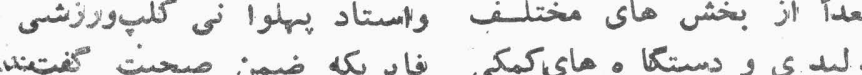

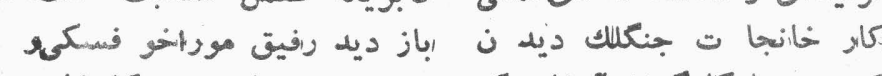

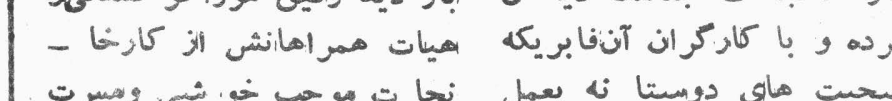

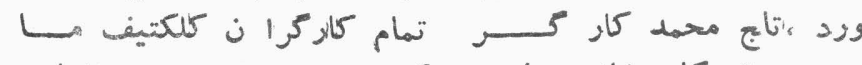

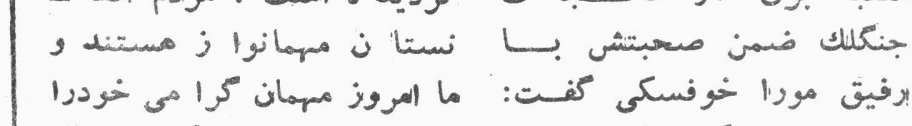

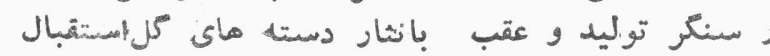

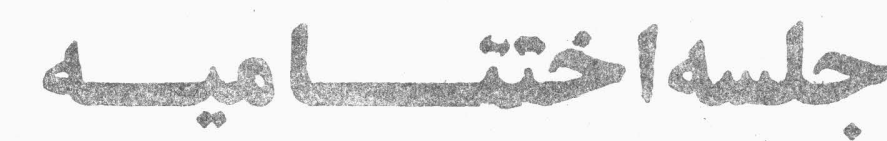

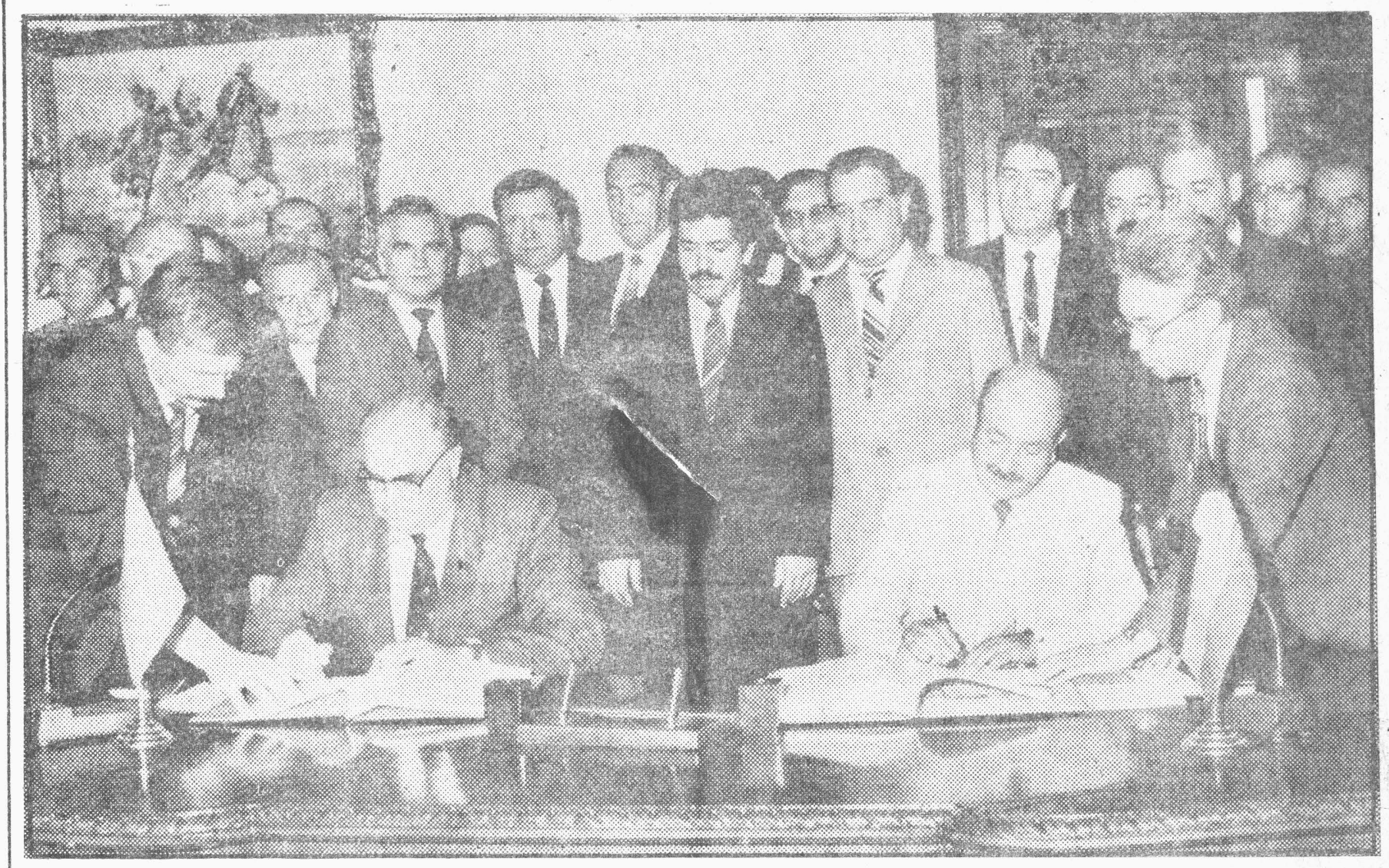

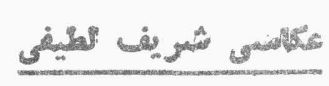

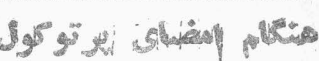




\section{كنف انس}
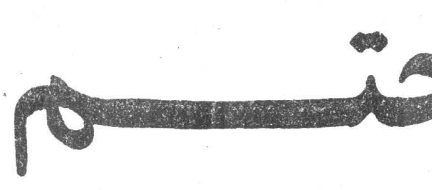

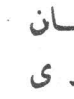

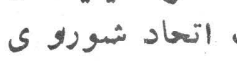

年

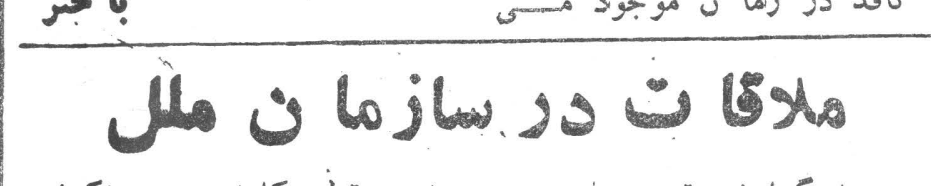

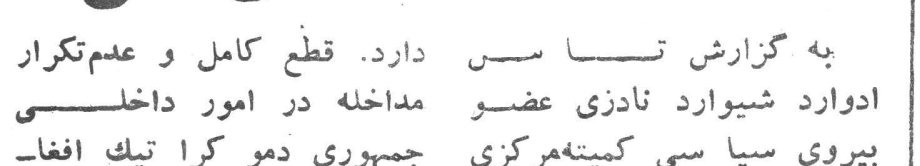

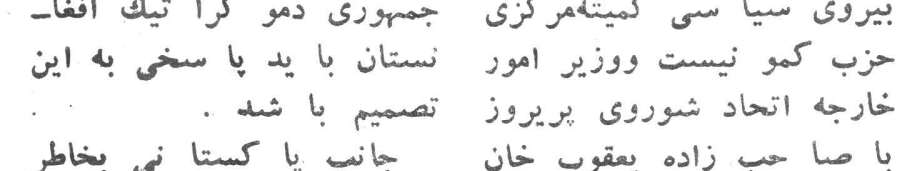

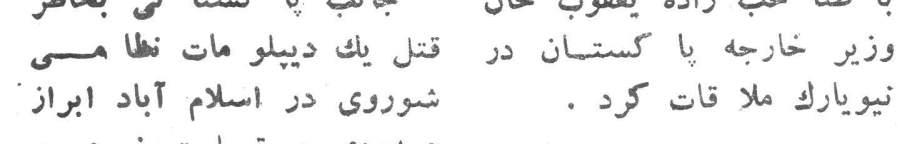

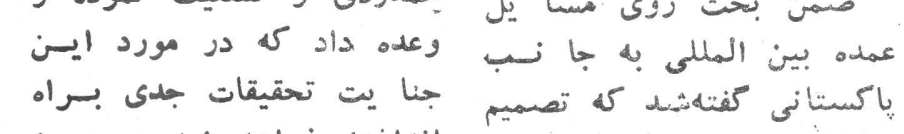

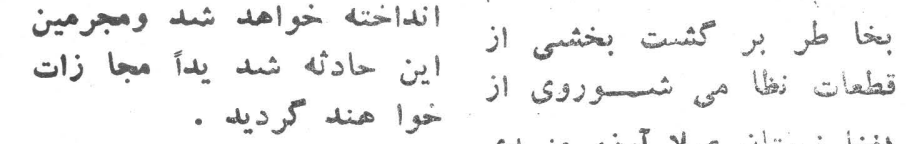

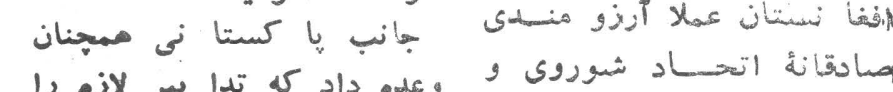

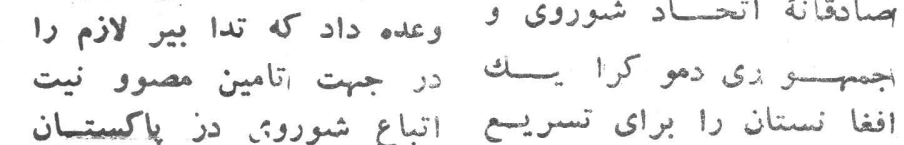

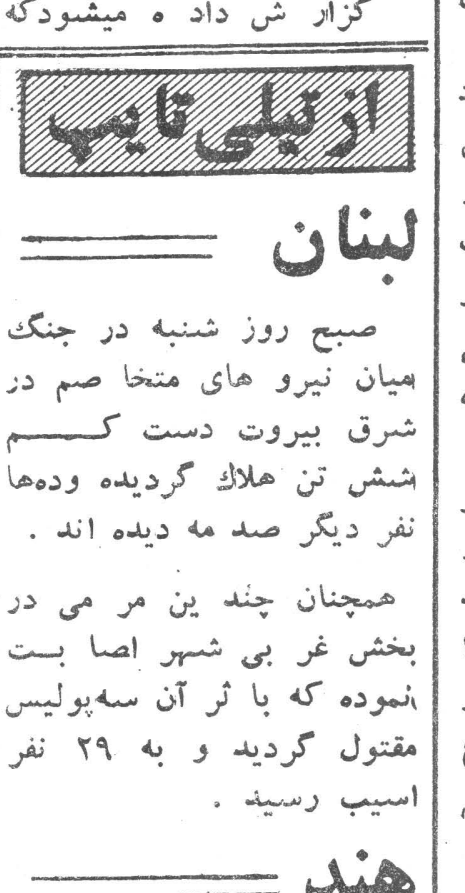

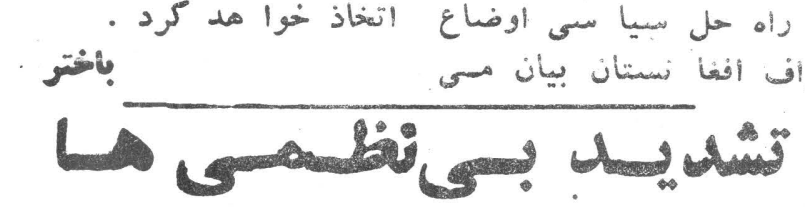

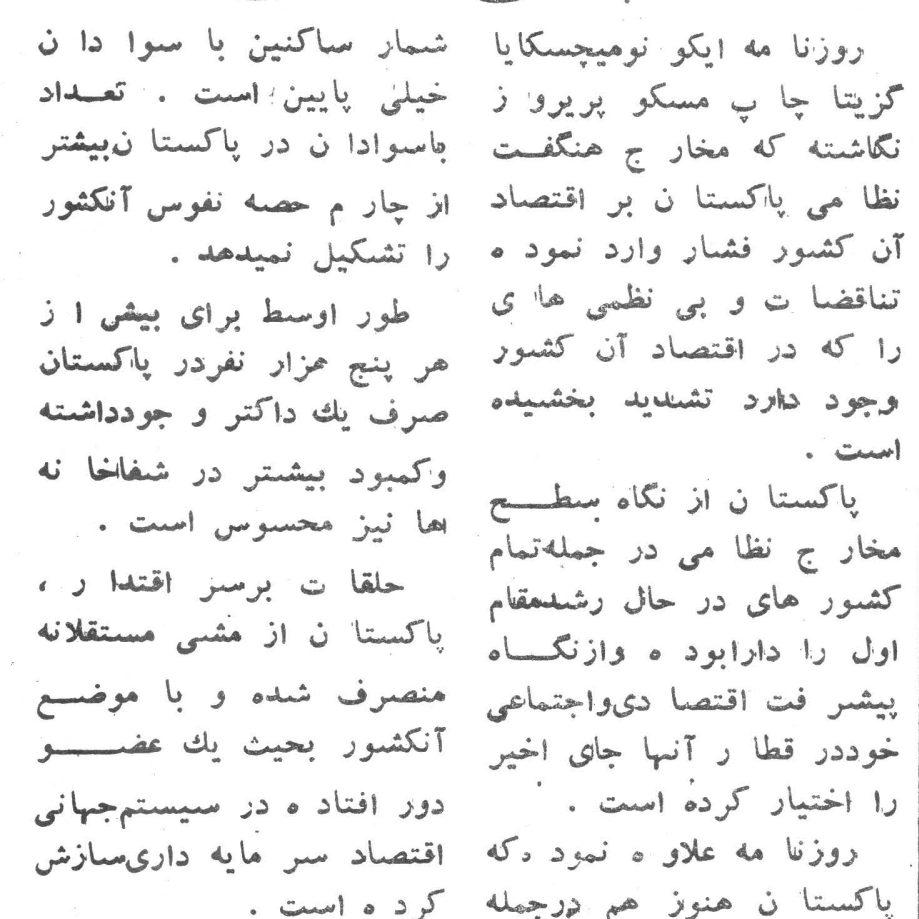


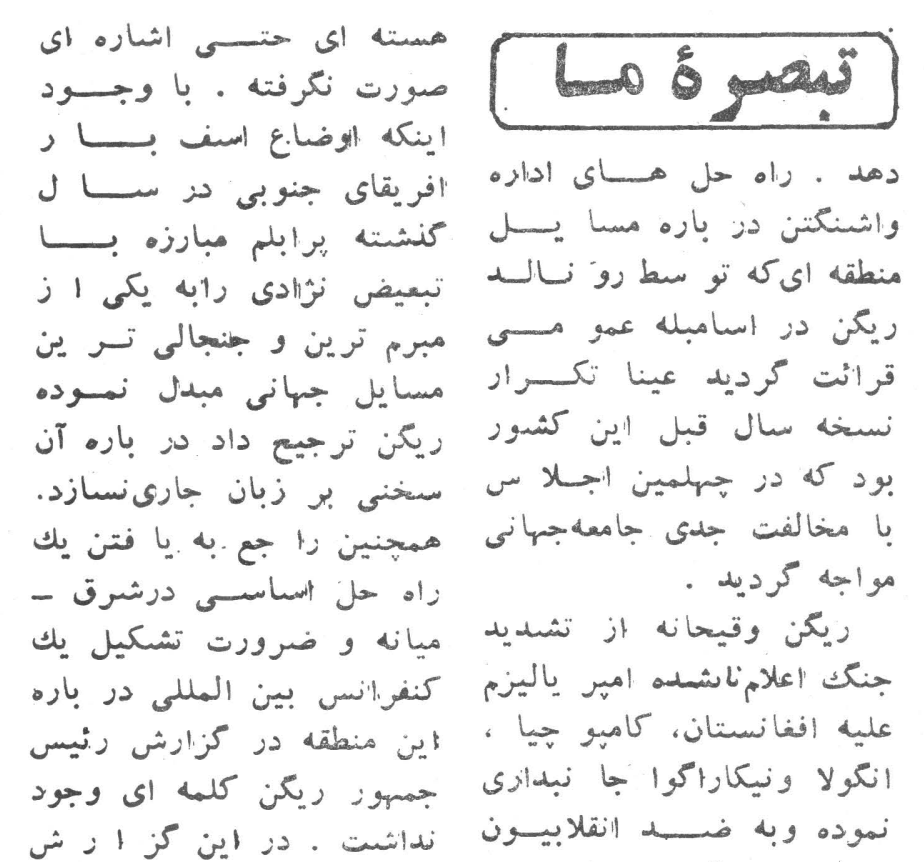

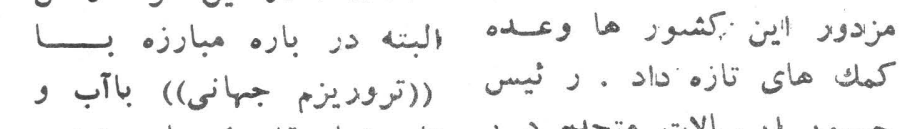

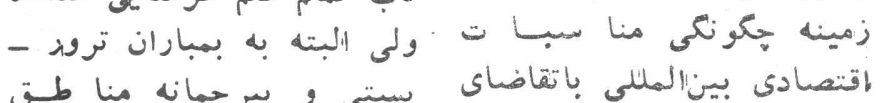

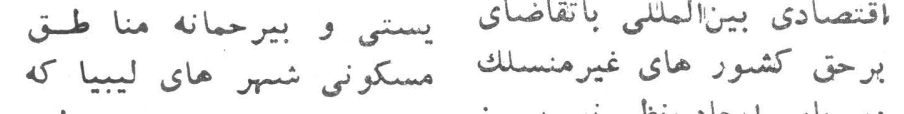

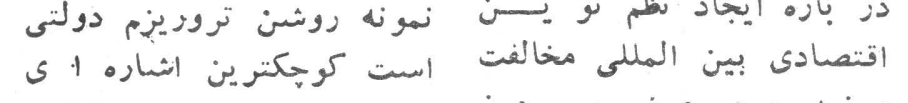

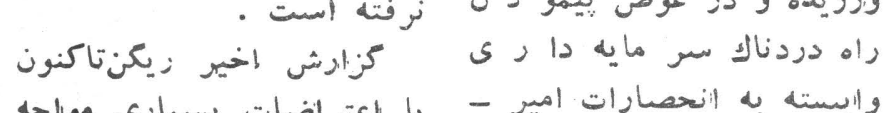

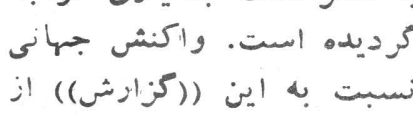

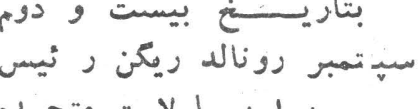

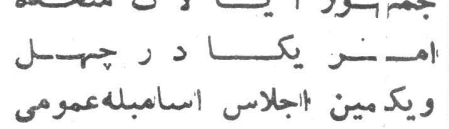

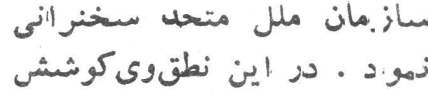

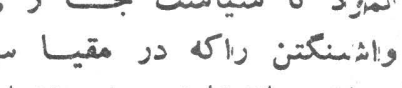

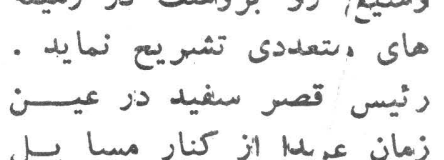

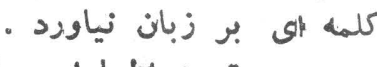

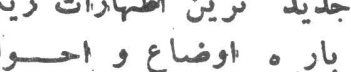

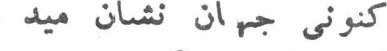

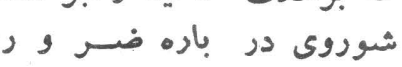

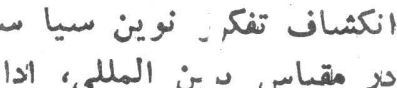

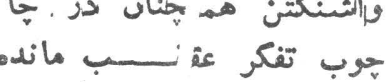

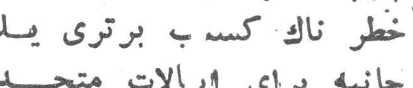

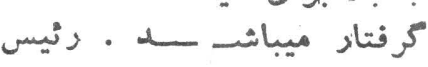

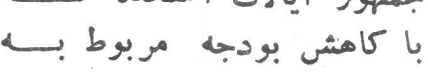

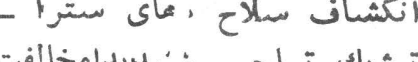

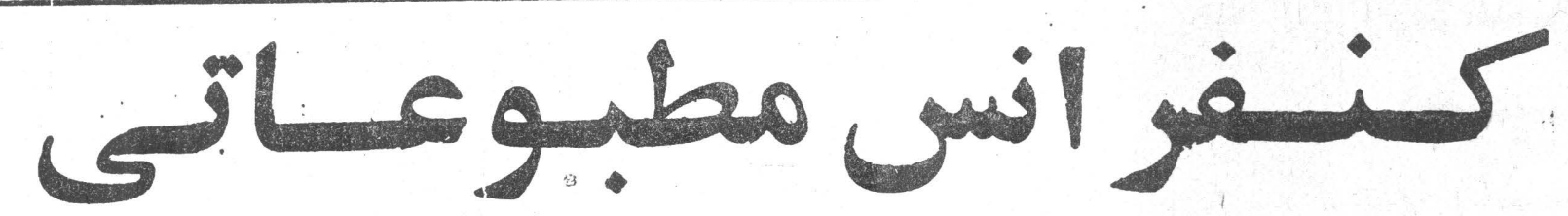

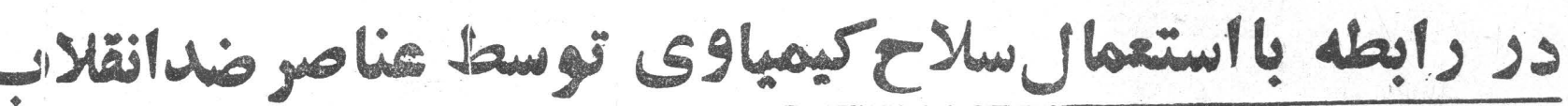

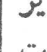
وافي

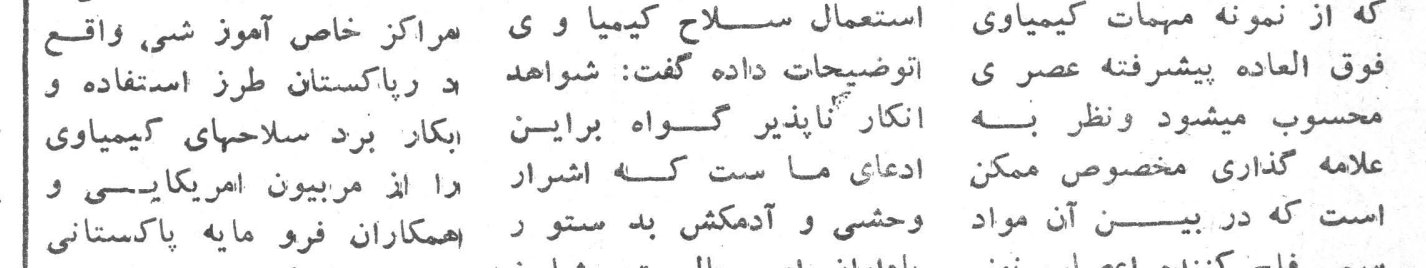

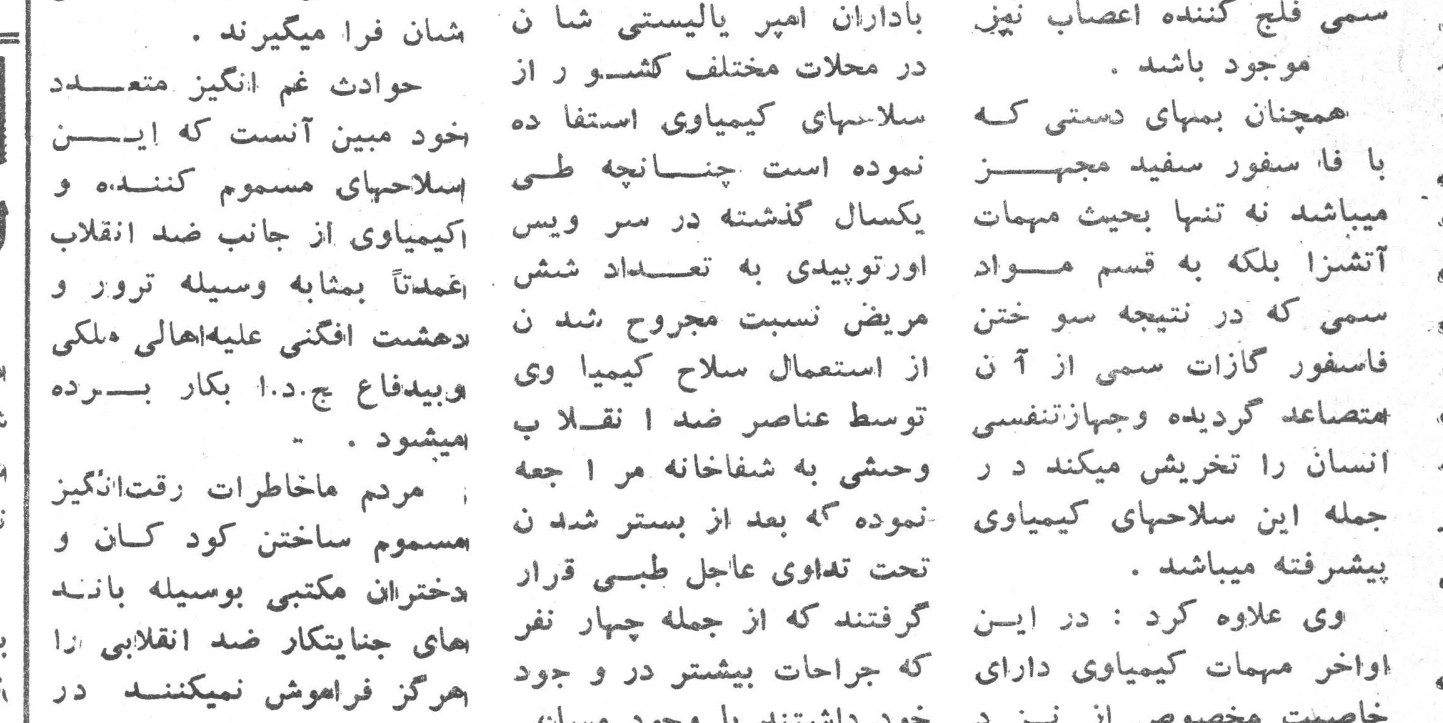

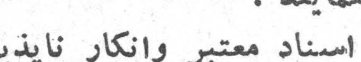

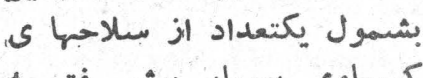

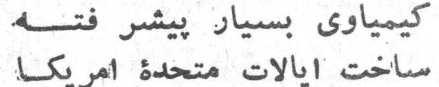
كا جهت مرك و ويرانسي

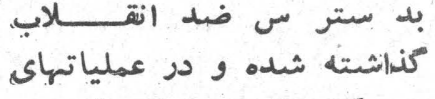
سر كوبى اشراد توسط قواى

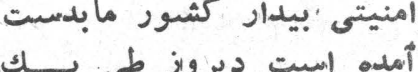

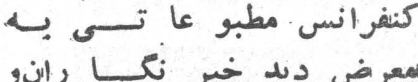

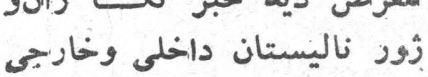

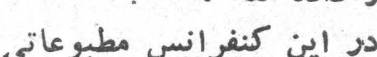

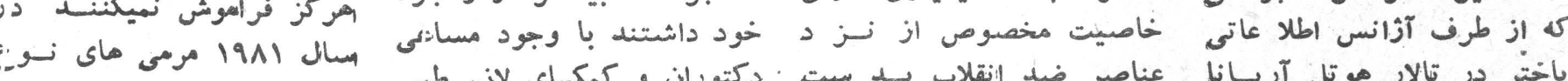

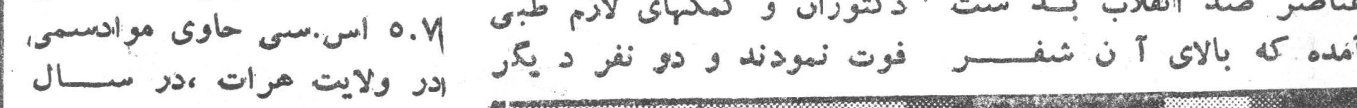

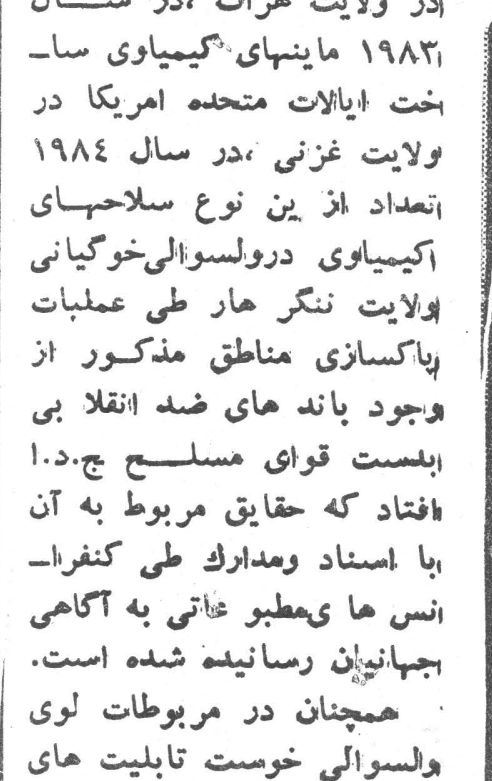

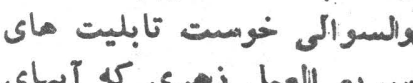

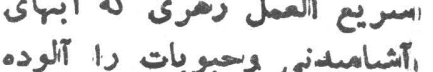

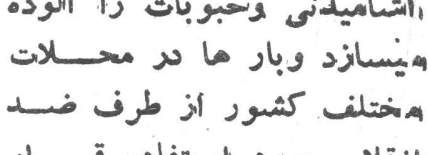

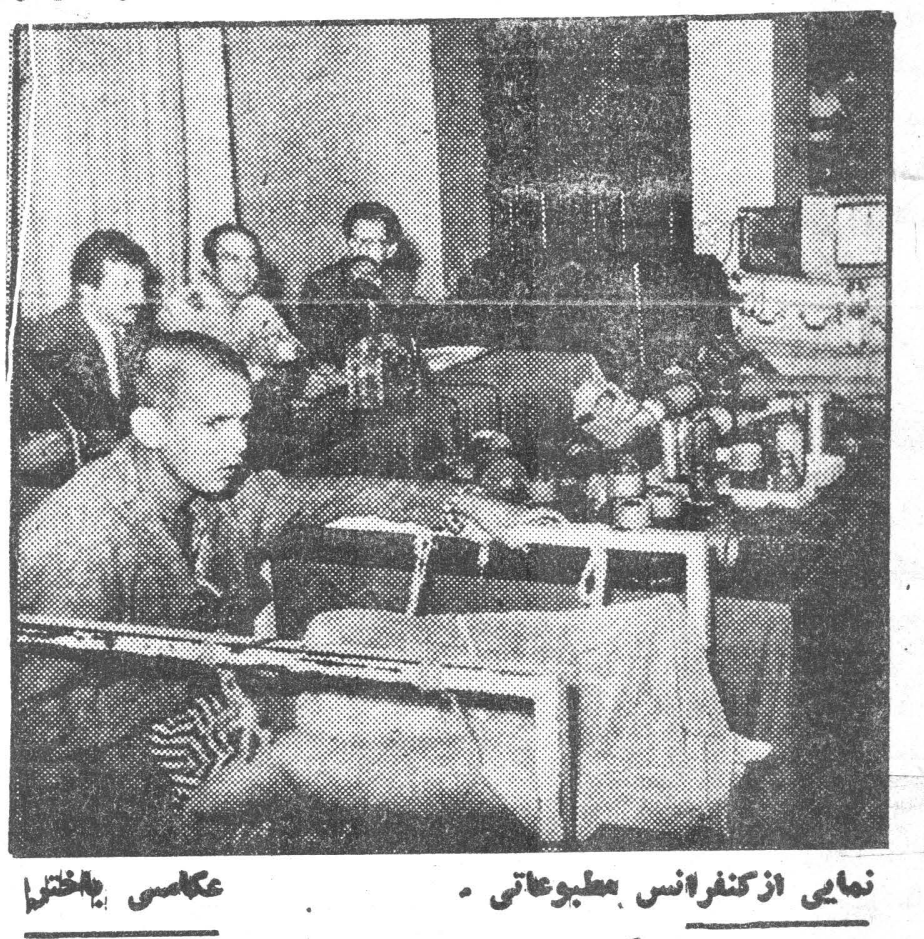

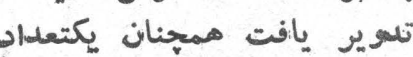

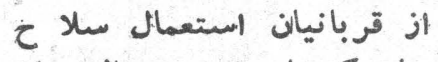

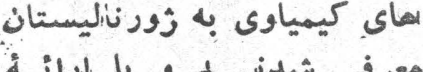

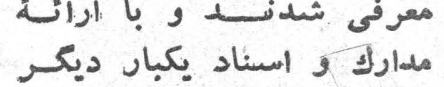

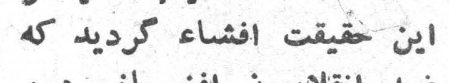

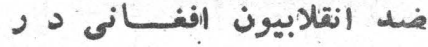

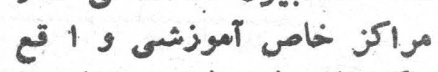

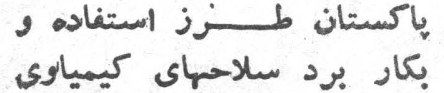

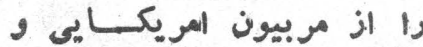

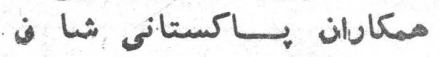

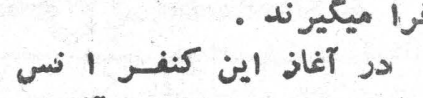

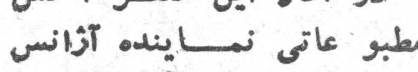

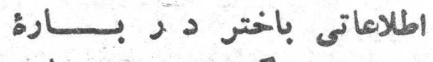

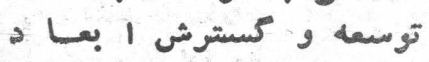

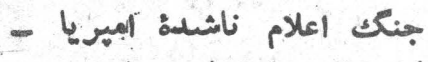

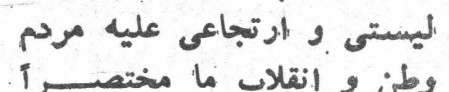

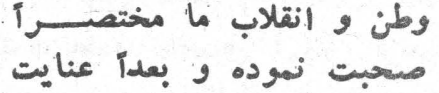
نبيل نماينده وزارت المستورد

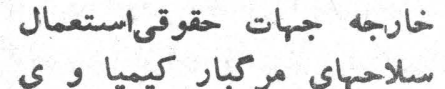

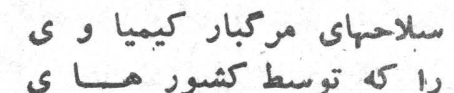

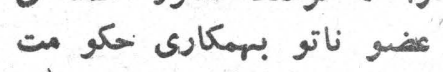

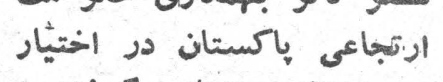

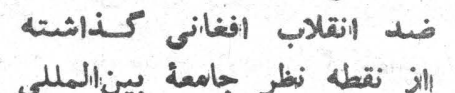

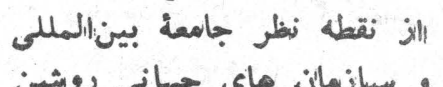

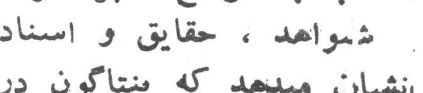

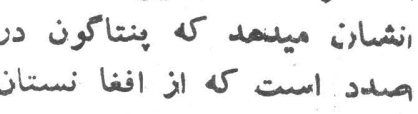

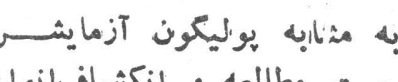

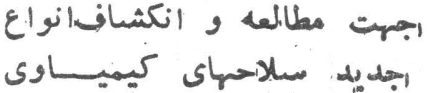

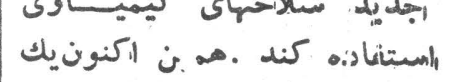

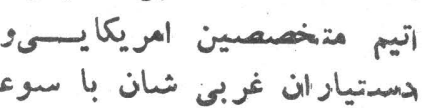

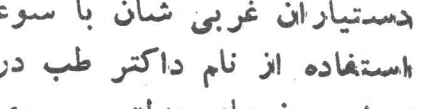

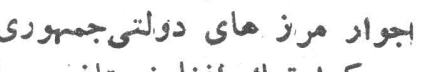

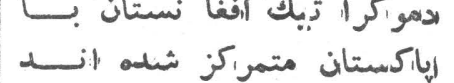

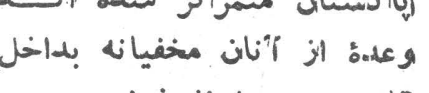

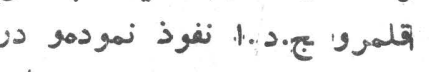

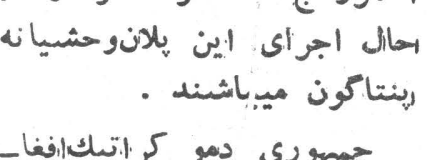

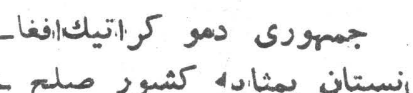

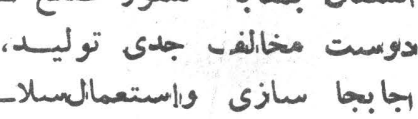

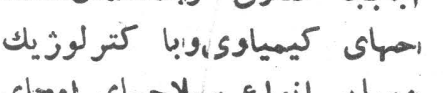

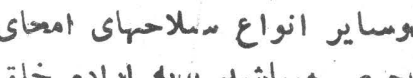

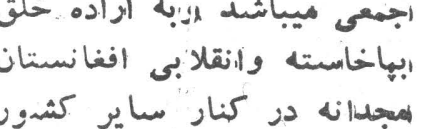

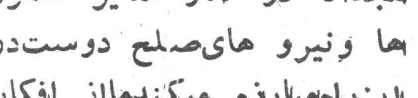

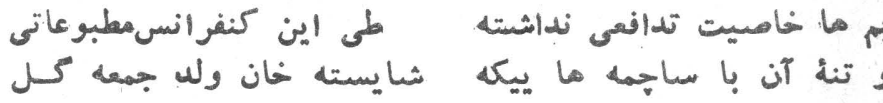

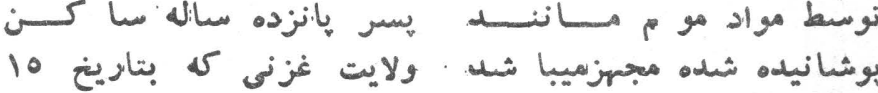

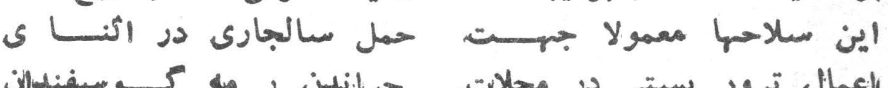

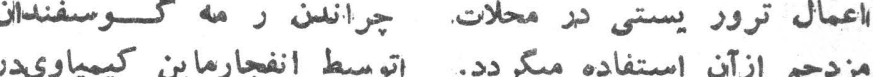

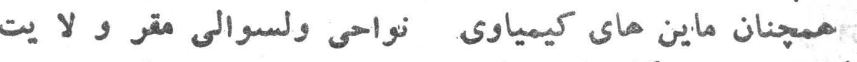

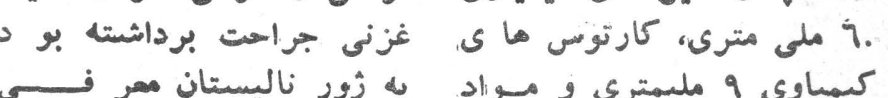

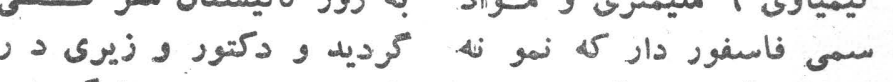

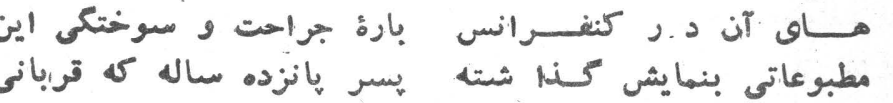

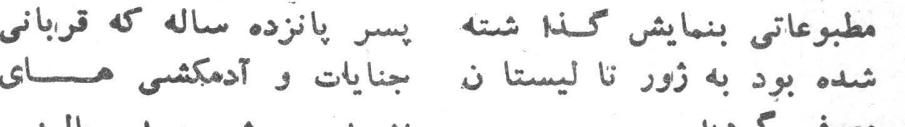

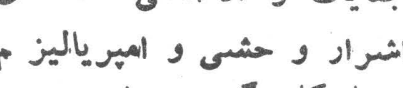

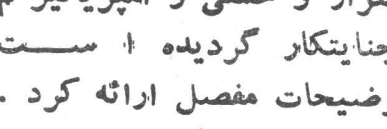

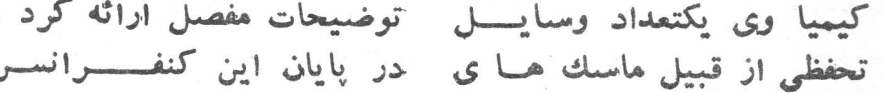

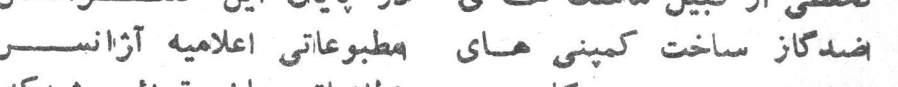

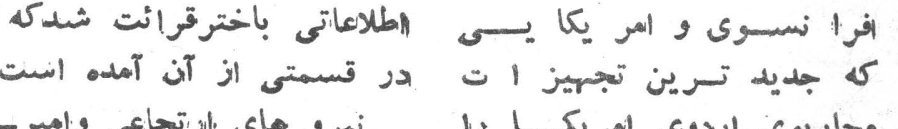

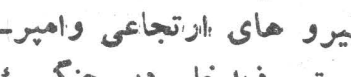

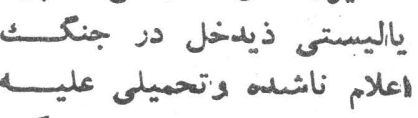

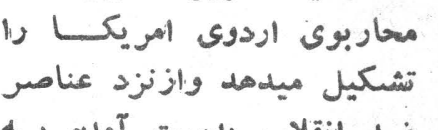

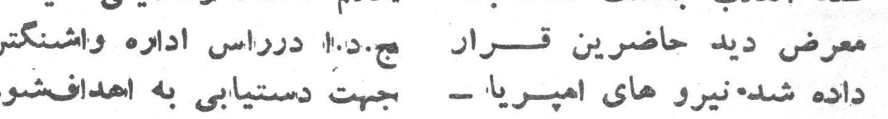

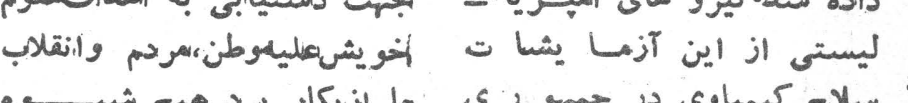

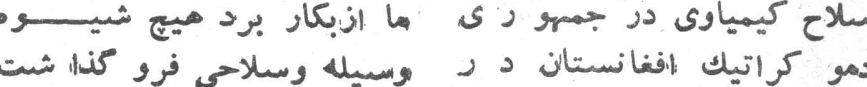

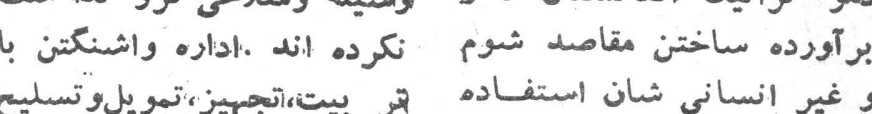

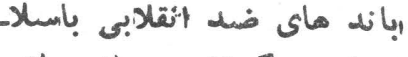

وى به نماينثاكى الز وزارت خارجئ جمهورى دمو كراتيك

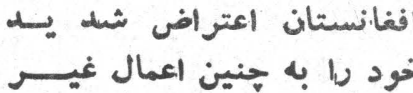

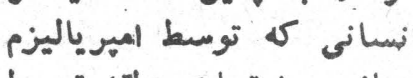

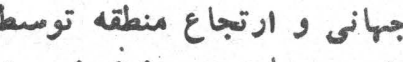

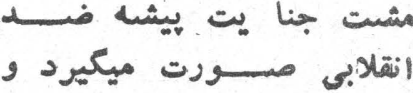

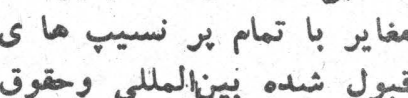

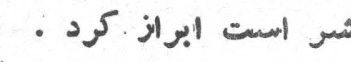

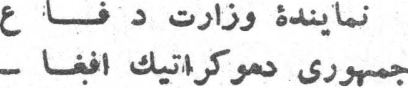

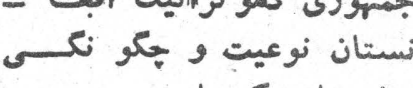

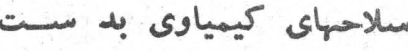

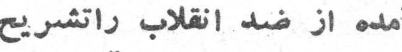

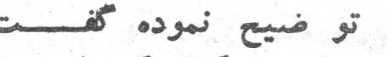

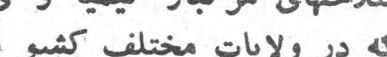

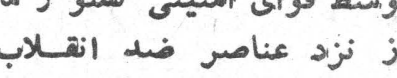

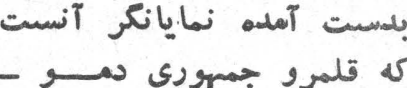
كراتيك افغانستان يواليكو نو ند

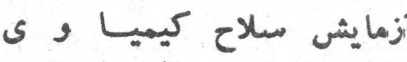
كثور هاى امبرياليستى قراد

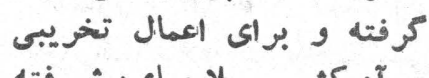
كيمياوى ساخت كثور ماني

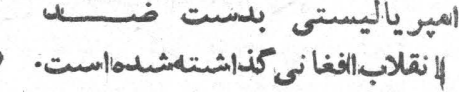

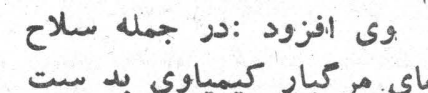

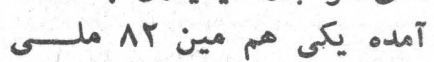

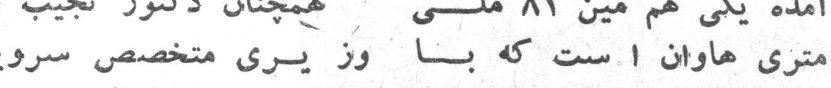

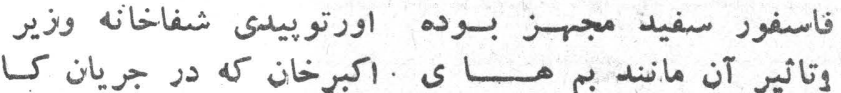

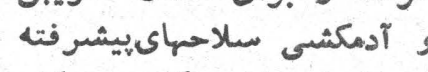



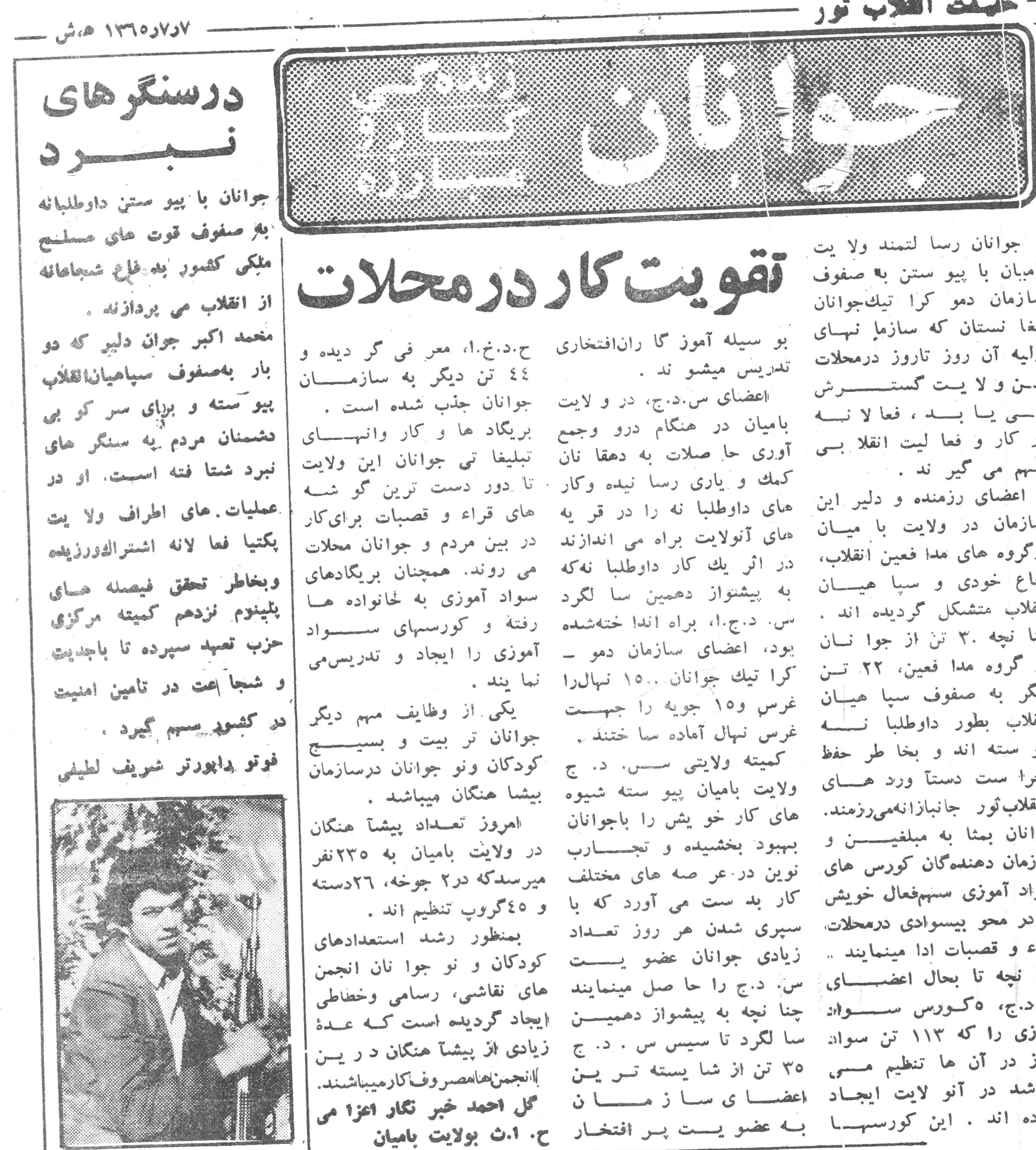

تقويتكار

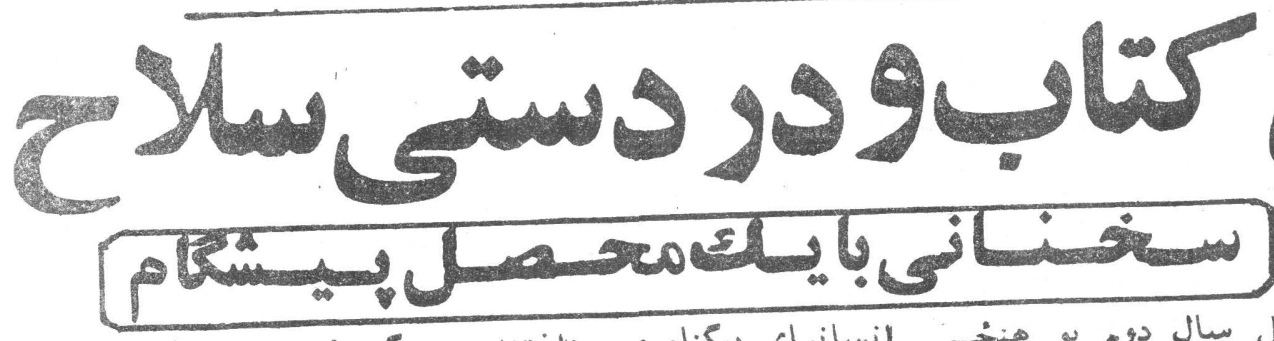
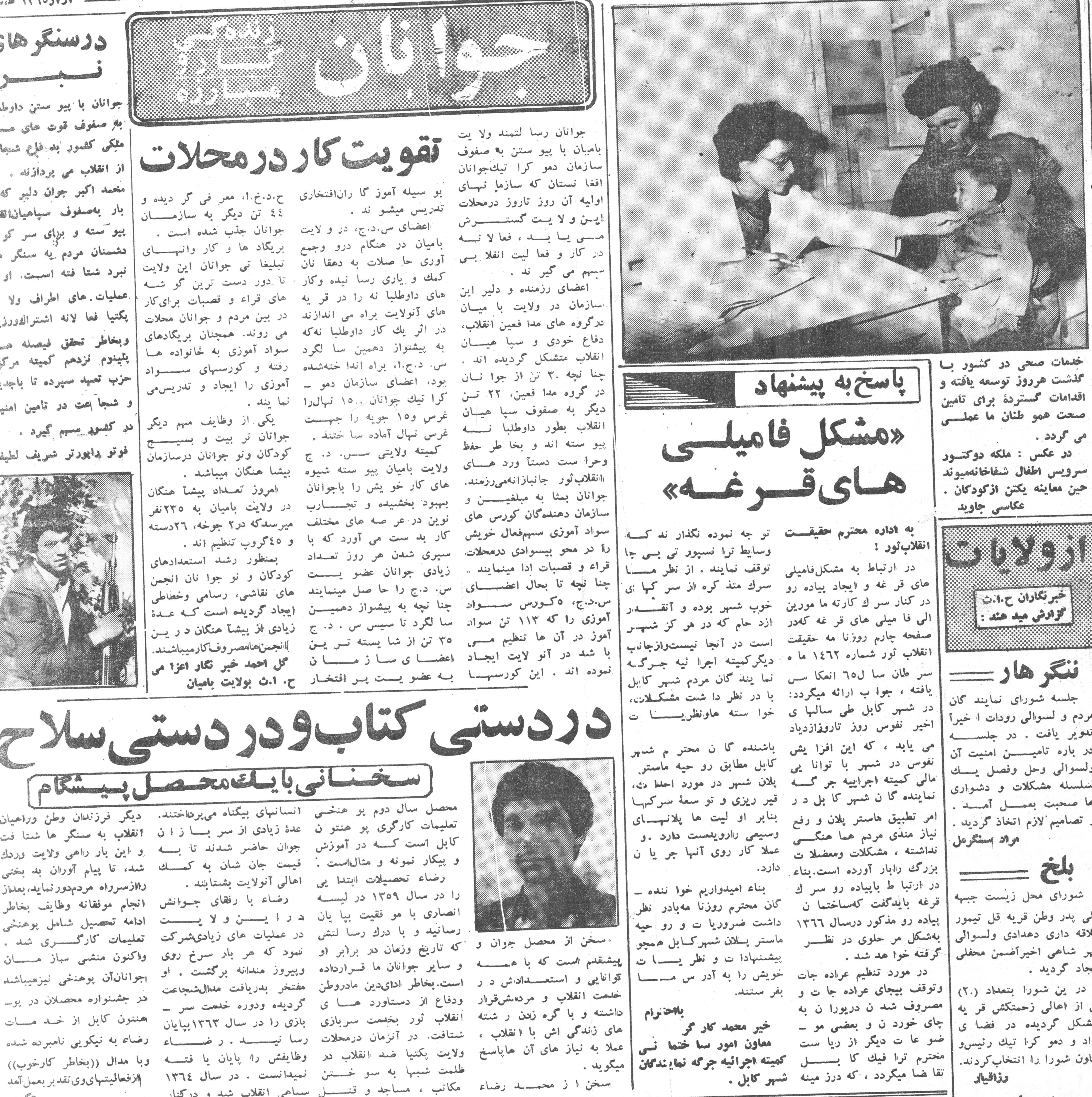

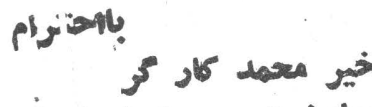

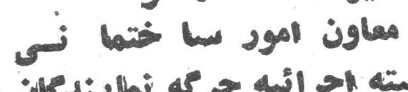

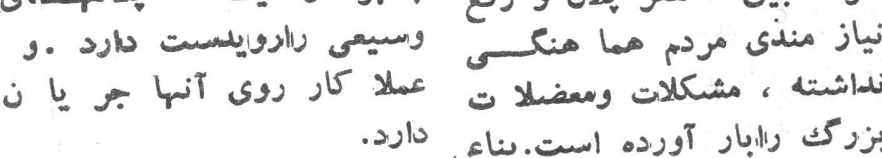

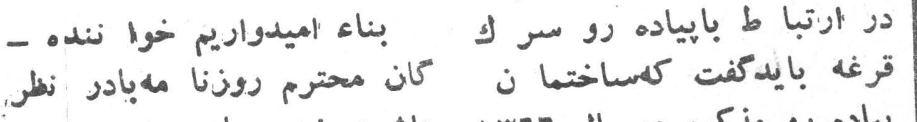

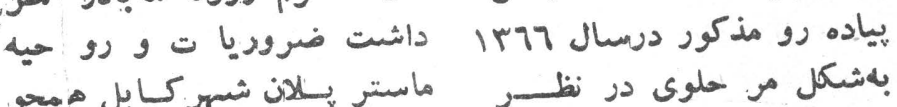

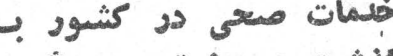

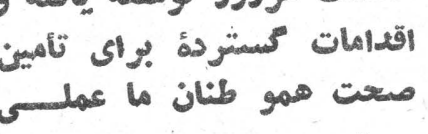
در عردس : ملكه دوكتسود

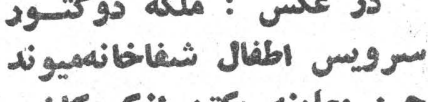
حين معاينه يكتن ازكودكان عكاسى جاويد

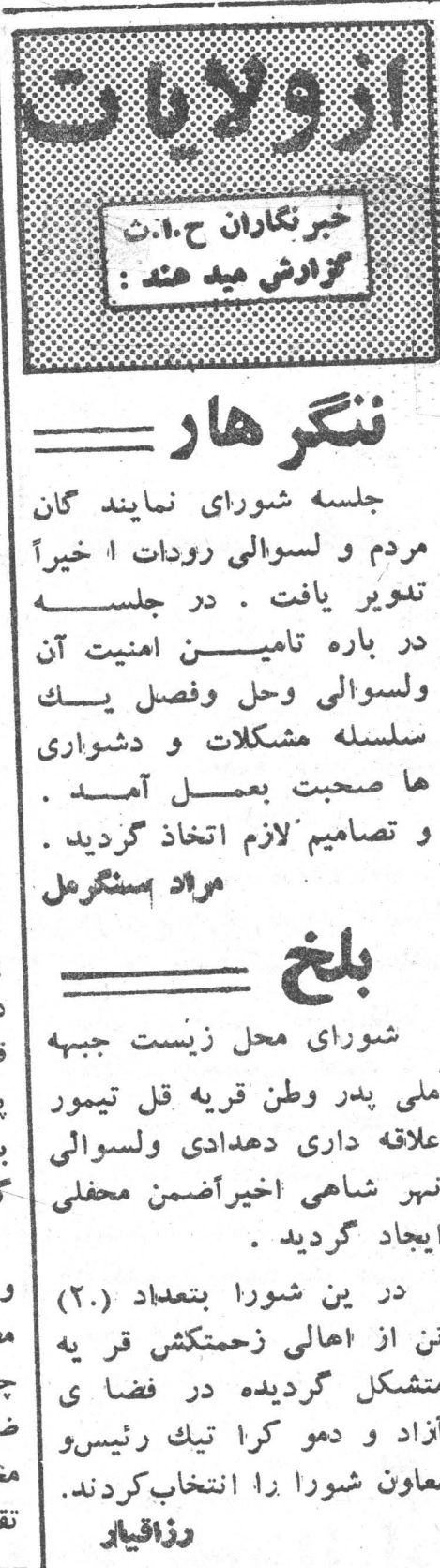

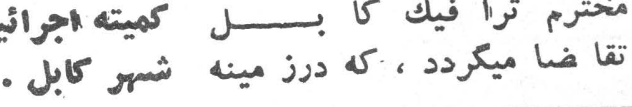

وزانيات 